\title{
Spirulina fusiformis: A Food Supplement against Mercury Induced Hepatic Toxicity
}

\author{
Madhu Kumar,* Mukesh Kumar Sharma, ${ }^{1}$ and Ashok Kumar \\ Cell and Molecular Biology Laboratory, Department of Zoology, University of Rajasthan, Jaipur-302004, India
}

(Received January 28, 2005; Accepted April 18, 2005)

\begin{abstract}
The protective effect of Spirulina fusiformis extract against mercury toxicity studied in Swiss albino mice. Animals treated with $\mathrm{HgCl}_{2}(5.0 \mathrm{mg} / \mathrm{kg}$ b.wt. i.p.) showed a significant elevation in lipid peroxidation level (LPO), aspartate amino transferase (AST) and alanine amino transferase (ALT) activity. However, a marked decline in serum alkaline phosphatase activity and reduced glutathione (GSH) content was recorded. Whereas, animals treated with Spirulina fusiformis extract ( $800 \mathrm{mg} / \mathrm{kg}$ b.wt. orally) before and after mercury intoxication showed a significant decrease in LPO level, AST and ALT activity and increase in serum alkaline phosphatase activity and GSH content. Spirulina fusiformis alone treatment did not alter reduced glutathione, AST, ALT and alkaline phosphatase activity but significantly diminishes the LPO level. Thus, the results obtained from the present study suggest that oral administration of Spirulina fusiformis extract provides protection against mercuric chloride induced toxicity in Swiss albino mice.
\end{abstract}

Key words — liver, mercuric chloride, Spirulina fusiformis, lipid peroxidation, glutathione

\section{INTRODUCTION}

Mercury and its compounds widely used in variety of products and processes, including pressure sensitive devices (thermometers, barometers) electrical apparatus (wiring, switches, batteries), paints, pharmaceuticals and in the production of various chemicals, known to be one of the most highly toxic metal to man (ATSDR, 1989'); Girardi and Elias, $1993^{2)}$ ). It is a transition metal, promotes the formation of reactive oxygen species (ROS) such as hydrogen peroxide. These ROS enhances the subsequent iron and copper-induced production of lipid peroxides and the highly reactive hydroxyl radical. These lipid peroxides and hydroxyl radical may cause the cell membrane damage and thus destroy the cell.

Several naturally occurring dietary or non-dietary constituents, and parts of several species of edible plants having pharmacological activity, influence the antioxidant enzymes and provide protec-

\footnotetext{
'Present address: Department of Zoology, S.N.K.P. Govt. (P.G.) College Neem Ka Thana-332713; Distt-Sikar, India

*To whom correspondence should be addressed: Cell and Molecular Biology Lab, Department of Zoology, University of Rajasthan, Jaipur-302004, India. Tel.: +91-141-2711529; Fax: +91-141-2245725; E-mail: mamsjpr@yahoo.com
}

tion against free radical induced damage.

In recent years, Spirulina is gaining more attention from medical scientists as a neutraceutical and source of potential pharmaceuticals. It is blue green algae (mycobacterium) belonging to the family Oscillatoriaceae. Spirulina fusiformis possess potent antiviral activity (Hayashi et al., 1996) ${ }^{3)}$ anticancer effects (Mittal et al., 1999), ${ }^{4)}$ strengthens immune system (Qureshi et al., 1995; 1996), ${ }^{5,6}$ radioprotective (Verma, 2000) ${ }^{7}$ and metalloprotective effects (Shastri, 19998); Saxena and Kumar, 2004 ${ }^{9}$ ).

Keeping in view the pharmacological properties of Spirulina fusiformis, present investigation was undertaken to assess the protective effect of Spirulina fusiformis extract against mercuric chloride induced hepatic toxicity in Swiss albino mice.

\section{MATERIALS AND METHODS}

Animals — Adult male Swiss albino mice (68 weeks old, weighing $23 \pm 2 \mathrm{~g}$ ) from an inbred colony (Procured from IVRI — Izzat Nagar) maintained at the animal house of the department were used for the present study. The animals were maintained on the standard mice feed and water ad libitum. Tetracycline water, once in fortnight was given as a preventive measure against infection. 
Spirulina fusiformis - Spirulina fusiformis in the form of powder was obtained from RECON Ltd., Banglore, India. It was suspended in vehicle (olive oil) and $0.05 \mathrm{ml}$ of Spirulina suspension was given to each mouse by oral gavage daily.

Mercuric Chloride - Mercury in the form of $\mathrm{HgCl}_{2}$ was obtained from Merck India Ltd. (Mumbai, India). It was dissolved in $0.9 \% \mathrm{NaCl}$ and administered i.p.

Experimental Design — The animals (Swiss albino mice) were divided into the following 4 groups.

Group I $(n=30)$ : No treatment was given to these animals.

Group II $(n=30)$ : The animals were given orally Spirulina fusiformis extract $(800 \mathrm{mg} / \mathrm{kg}$ b.wt. in olive oil) for 30 consecutive days.

Group III $(n=30)$ : These animals were administered $\mathrm{HgCl}_{2} 5.0 \mathrm{mg} / \mathrm{kg}$ b.wt. in $0.9 \% \mathrm{NaCl}$ intraperitonially.

Group IV $(n=30)$ : In this group of animals, Spirulina extract $800 \mathrm{mg} / \mathrm{kg}$ b.wt. was given orally for 10 consecutive days, before mercuric chloride $(5.0 \mathrm{mg} / \mathrm{kg}$ b.wt.) administration and until 30 days of mercuric chloride administration.

The animals from the above groups were autopsied at 1, 3, 7, 15 and 30th days after mercuric chloride administration. The liver was excised out and processed for histological and biochemical alterations. Blood from these animals was collected by cardiac puncture and serum was separated and processed for liver function tests.

Histopathological Studies — Liver from autopsied animals were excised out and fixed in Bouins fixatives for 24-48 hr. Five-micron thick histological sections were prepared and stained with hematoxyline and eosin. These stained slides were observed under light microscope for histological alterations.

Liver Function Tests - To assess the liver functions following biochemical parameters were done in the serum.

Serum Alkaline Phosphatase: Serum alkaline phosphatase activity was measured by the method of Kind and King (1954),${ }^{10)}$ using commercially accessible kits (Span Diagnostics Ltd., Surat, India).

Principle: Alkaline phosphatase from serum converts phenyl phosphate to inorganic phosphate and phenol, at $\mathrm{pH}$ 10.0; phenol so formed reacts in alkaline medium with 4-amino antipyrine in the presence of an oxidizing agent, potassium ferricyanide, and forms an orange - red colored complex, which can be measured colorimetrically or spectrophoto- metrically at $510 \mathrm{~nm}$. The color intensity is proportional to the enzyme activity, which is expressed as Kings and Armstrong Unit (KAU).

Serum Aspartate Amino Transferase (AST): The aspartate amino transferase activity was estimated by the method of Reitman and Frankel, (1959). ${ }^{11)}$

Principle: Aspartate amino transferase (AST) catalyses the conversion of $\alpha$-ketoglutarate and aspartate into glutamate and oxaloacetate respectively. Oxaloacetate so formed is coupled with 2,4 dinitrophenyl hydrazine (DNPH) to give the corresponding hydrazone, which gives brown color in alkaline medium and this is measured colorimetrically.

Standard Curve: Standard curve was obtained using different amounts of pyruvate and enzyme activity was expressed as units/ml.

Serum Alanine Amino Transferase (ALT): The alanine amino transferase activity was measured by the method of Reitman and Frankel (1959) ${ }^{11)}$ using DNPH as a colour reagent.

Principle: Alanine amino transferase (ALT) catalyses the conversion of $\alpha$-ketoglutarate and alanine into glutamate and pyruvate respectively. Pyruvate so formed is coupled with DNPH to give the corresponding hydrazone, which gives brown color in alkaline medium and this can be measured colorimetrically.

Standard Curve: Standard curve was obtained using different amounts of pyruvate and enzyme activity was expressed as units $/ \mathrm{ml}$.

\section{Biochemical Studies in Liver -}

Lipid Peroxidation (LPO) Assay: Lipid peroxidation (LPO) level in liver was estimated by the method of Ohkawa et al. (1979) ${ }^{12}$ as thiobarbituric acid reactive substances (TBARS). The concentration of TBARS was exposed as $n$ moles of malondialdehyde per mg of tissue using 1, 1, 3, 3tetramethoxy propane (TMP) as the standard.

Principle: Malondialdehyde (MDA) formed from the breakdown of polyunsaturated fatty acids serves as a convenient index for determining the extent of the peroxidation reaction. Peroxidation of lipids generates MDA, which reacts with thiobarbituric acid to give a red species absorbing $532 \mathrm{~nm}$.

Reduced Glutathione: The liver reduced glutathione (GSH) level as determined by the method of Moron et al. (1979). ${ }^{13)}$

Principle: The Reduced Glutathione reacts with 5',5'-dithiobis(2-nitrobenzoic acid) (DTNB) and forms a yellow coloured complex with DTNB that 


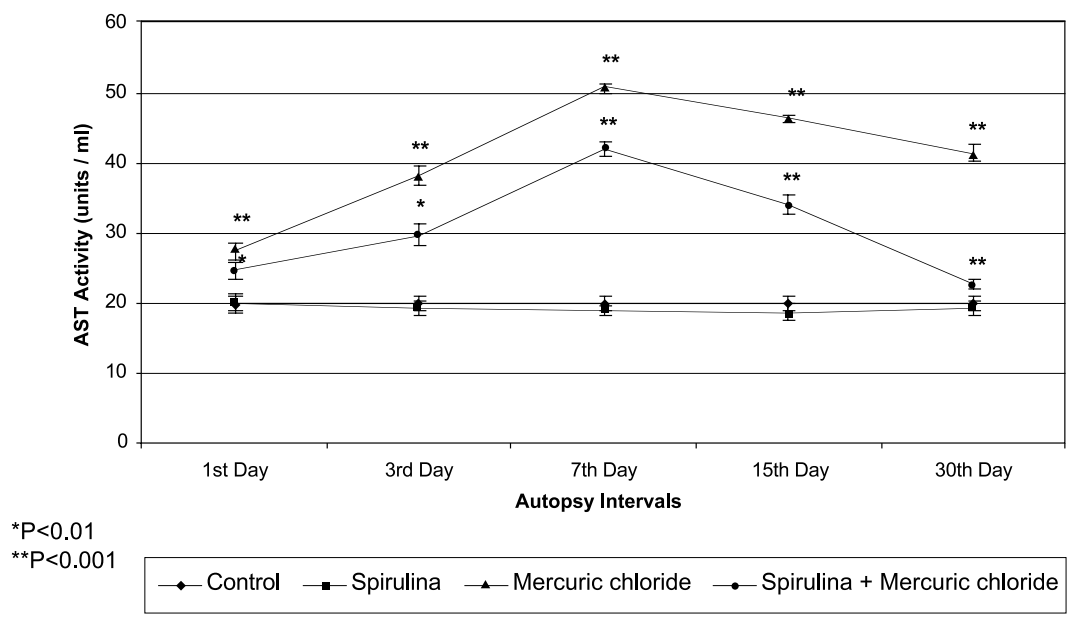

Fig. 1. Variation in AST Activity in Different Experimental Groups

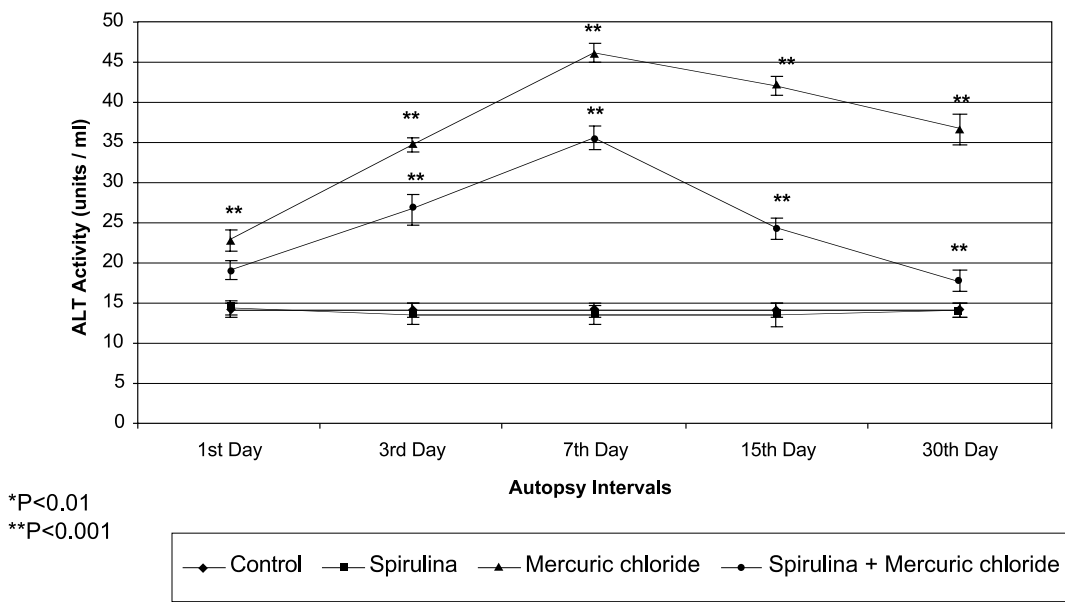

Fig. 2. Variation in ALT Activity in Different Experimental Groups

absorbs at $412 \mathrm{~nm}$.

The tissue homogenates $(10 \% \mathrm{w} / \mathrm{v})$ were immediately precipitated with $0.1 \mathrm{ml}$ of $25 \%$ tri chloro acetic acid (TCA), and the precipitate was removed after centrifugation. Free endogenous GSH was assayed in a total $3 \mathrm{ml}$ volume by the addition of $2 \mathrm{ml}$ of $0.5 \mathrm{mM}$ DTNB prepared in $0.2 \mathrm{~m}$ phosphate buffer $(\mathrm{pH}=8.0)$ to $0.1 \mathrm{ml}$ of the supernatant, and the absorbance was read at $412 \mathrm{~nm}$ using a UV-visible (UV-VIS) Systronic Spectrophotometer. GSH was used as a standard to calculate $\mu$ mole $\mathrm{GSH} / \mathrm{g}$ tissue.

Statistical Analysis - The values were expressed as mean \pm SEM. The data were subjected to student's $t$-test for comparison between the groups.

\section{RESULTS}

\section{Histological Studies}

$\mathrm{Hg}$ intoxication produced various pathological lesions in the liver such as cytoplasmic vacuolisation, karyorhexis, karyolysis, pycnosis and centrilobular necrosis. On day 1 st hepatocytes showed fragmented or lysed nuclear material. Congestion of sinusoidal spaces was also prominent. From day 3rd to 15 th pathological signs were more prominent, hepatocytes showed massive centrilobular as well as peripheral necrosis. Cytoplasmic vacuolisation, enucleation, karyorhexis, karyolysis and pyknosis were also evident. At the day 30th the liver showed slight recovery as compared to day 15 th. Pre and post treatment of Spirulina with mercury showed prominent recovery. There was reduced cytoplasmic vacuolisation and centrilobular necrosis observed as compared to 


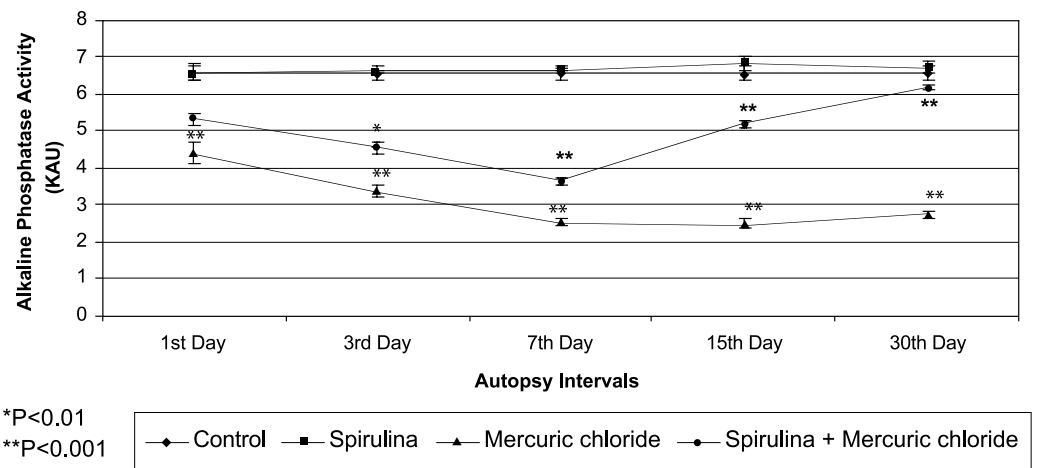

Fig. 3. Variation in Serum Alkaline Phosphatase Activity in Different Experimental Groups

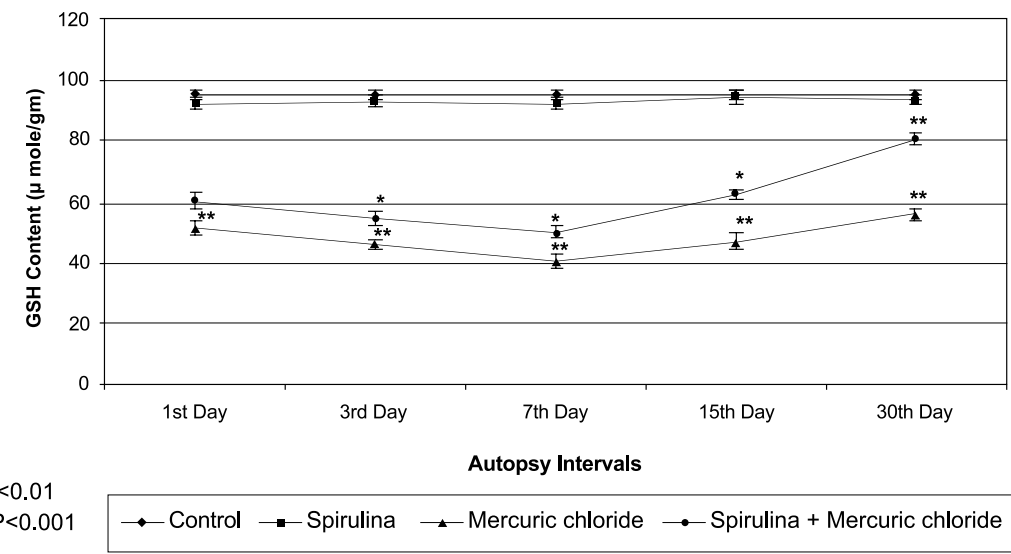

Fig. 4. Variation in Hepatic GSH Content in Different Experimental Groups

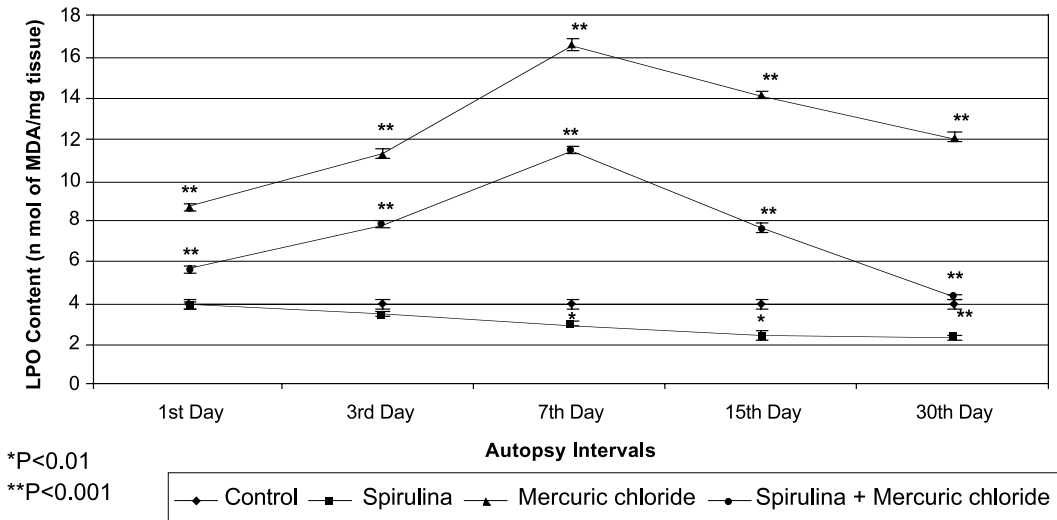

Fig. 5. Variation in Hepatic LPO Content in Different Experimental Groups

$\mathrm{Hg}$ intoxicated mice. Upto day 30th hepatocytes were become normal with prominent nuclei and wellmarked granulated hepatocytoplasm.

\section{Biochemical Studies}

Spirulina Treated Animals: The animals treated with Spirulina extract (Group II) alone did not ex- hibited any significant alteration in hepatic glutathione, alkaline phosphatase, ALT and AST activity during the entire period of study and values remained near normal. A significant decrease in LPO level was observed (Figs. 1-5) throughout the experimental period as compared to normal animals.

$\mathrm{HgCl}_{2}$ Treated Animals: Animals treated with 
$\mathrm{HgCl}_{2}$ (Group III) showed a significant elevation in AST, ALT and LPO level $(p<0.001)$. A maximum increase was observed at day 7 th and afterwards a decline was observed (day 15th and 30th). However, a marked decrease in serum alkaline phosphatase activity and GSH content was recorded at all autopsy intervals and a maximum decline was noticed at day 15 th $(p<0.001)$ and day 7 th respectively (Figs. 1-5).

Combination Group: In the combination group (Group IV) where animals were treated with the Spirulina and $\mathrm{HgCl}_{2}$, significant decline in activity of AST, ALT, and LPO level was noticed throughout all autopsy intervals as compared to $\mathrm{HgCl}_{2}$ treated animals (Group III) and the values returned to normal on day 30th. Whereas, a significant elevation in serum alkaline phosphatase activity and GSH content was observed throughout the experimentation period as compared to $\mathrm{HgCl}_{2}$ treated animals. (Group III) (Figs. 1-5).

\section{DISCUSSION}

Mercury intoxication showed a significant increase in transaminases (AST and ALT) activities. The increase in AST and ALT in serum may be due to hepatocellular necrosis, which causes increase in the permeability of the cell membrane resulting in the release of transaminases in the blood stream (Vandenberghe, 1995 ${ }^{14)}$; Rana et al., 1996 ${ }^{15}$; Sharma et al., 2002 ${ }^{16)}$ ). This confirms our earlier report on histopathological changes in liver induced by $\mathrm{HgCl}_{2}$ intoxication (Sharma et al., 2000; 2001; 2002). ${ }^{16-18)}$

Further, there was a significant decrease in the serum alkaline phosphatase activity after $\mathrm{HgCl}_{2}$ intoxication. In the liver, it is closely connected with lipid membrane in the canalicular zone, so that any interference with the bile flow, whether extra hepatic or intra hepatic leads to decrease in serum alkaline phosphatase activity (Vandenberghe, 1995; Sharma et al., 2002). ${ }^{16)}$ Mercury causes cell membrane damage (lipid peroxidation), which leads to the imbalance between synthesis and degradation of enzyme protein, thus lowering the enzyme activity (Hardonk and Koudstaal, 1976). ${ }^{19)}$ Present findings are in agreement with the findings of El-Demerdash, $(2001)^{20)}$ and Sharma et al. (2002). ${ }^{16)}$ They observed that $\mathrm{HgCl}_{2}$ intoxication $(0.5 \mu \mathrm{mol} / \mathrm{ml}$ and $5.0 \mathrm{mg} / \mathrm{kg}$ body weight) significantly decreases the alkaline phosphatase activity.

GSH is the major thiol, which binds electrophilic molecular species and free radical intermediates. It plays a central role in the antioxidant defence system, metabolism and detoxification of exogenous and endogenous substances. (Ketterer et al., 1983 ${ }^{21)}$; Meister and Andersen, 198322). Mercury is a transition metal and has high affinity with GSH and causes the irreversible excretion of up to two GSH tripeptides (Zalups and Lash, 1996). ${ }^{23)}$ The metalGSH conjugation process is desirable in that it results in the excretion of the toxic metal into the bile. As a result of the binding of mercury to glutathione and the subsequent elimination of intracellular glutathione, levels of reduced glutathione are lowered in the cell and thus decrease the antioxidant potential of the cell. In the present investigation it was observed that $\mathrm{Hg}$ intoxication significantly depletes the GSH content in the liver and thus reducing the antioxidant potential and accelerating the lipid peroxidation, resulting in hepatocytes damage.

It was observed that an extract of Spirulina when given in combination with mercuric chloride, significantly elevated liver GSH content and decline lipid peroxidation and reduces the mercury toxicity which in turn is reflected by significantly decrease in activity of serum transaminases (AST and ALT) and increase in serum alkaline phosphatase activity and reduces liver damages.

The protective efficacy of Spirulina fusiformis may be due to presence of several active components. The active component found in Spirulina may provokes the activity of free radical scavenging enzyme systems and renders protection against mercury induced liver damages. The metallo-protective role of Spirulina may be attributed to the presence of $\beta$-carotene (Prescott 1978 ${ }^{24)}$; Seshadri et al., $1991^{25)}$ ), vitamin C, E (Mathew et al., 1995) ${ }^{26)}$ enzyme superoxide dismutase (Ben Amotz, 198727); Henrikson, 1989 ${ }^{28)}$ ) and selenium (Henrikson, $\left.1989^{28}\right)$.

$\beta$-Carotene acts as powerful quencher of singlet oxygen and a scavenger of free radicals (Foote $e t$ al., 1970 ${ }^{29)}$; Krinsky and Deneke, 1982 $\left.{ }^{30)}\right)$. Luxia et al. $(1996)^{31)}$ reported that $\beta$-carotene of Spirulina may reduce cell damage, especially the damage to DNA molecules, thus playing the role in the repair of regeneration process of damaged hepatocytes cells.

Vitamin E of the Spirulina fusiformis prevents mercury induced lipid peroxidation and maintains intracellular thiols and ascorbic acid levels in damaged tissue by inhibiting free radical formation and oxidative damage (Duval and Poelman, 199422); Kulkarni and Bycz Kowski, 199733); Patil and Rao, 
$\left.1999^{34)}\right)$. According to Rao and Sharma (2001), ${ }^{35)}$ vitamin $\mathrm{E}$ showed protective effect against $\mathrm{HgCl}_{2}$ through impaired absorption of mercury in the gastrointestinal tract. Rana et al. (1996) ${ }^{15)}$ also postulated that vitamin $\mathrm{E}$ has a protective effect against mercury toxicity.

Selenium component in Spirulina induces selenium containing enzyme GSH peroxidase, proteins or compounds such as selenodiglutathione, selenocysteine and dimethylselenide, which are known to modulate the toxic effects of heavy metals (Henrikson, 198928); Lindh et al., 1996 $\left.{ }^{36}\right)$. Superoxide dismutase is a mitochondrial enzyme, which is found to quench free radicals and prevents tissue damage (Henrikson, 1989²); Girardi and Elias, $1995^{37)}$ ).

Spirulina also induces the activity of immune system. It builds up both the cellular and humoral arms of the immune systems and thus improving their ability to function inspite of stresses from environmental toxins and infectious agents (Hayashi et al., 1994 ${ }^{38)}$; Qureshi et al., 1995 ${ }^{6}$ ).

Acknowledgements Financial assistance provided by CSIR, New Delhi to M. K. Sharma is highly acknowledged. Authors are also thankful to Recon Limited, Banglore for providing Spirulina fusiformis.

\section{REFERENCES}

1) ATSDR (1989) Toxicological profile for mercury. In ATSDR/US. Public Health Service.

2) Girardi, G. and Elias, M. M. (1993) Effect of different renal glutathione levels on renal mercury disposition and excretion in the rat. Toxicology, 81, 51.

3) Hayashi, K., Hayashi, T. and Kojima, I. (1996) A natural sulfated polysaccharide, calcium spirulin, isolated from Spirulina platensis: in vitro and ex vivo evaluation of anti-herpes simplex virus and antihuman immuno-deficiency virus activities. AIDS Res. Hum. Reteroviruses, 12, 1463-1471.

4) Mittal, A., Suresh Kumar, P. V., Banerjee, S., Rao, A. R. and Kumar, A. (1999) Modulatory potential of Spirulina fusiformis on carcinogen metabolizing enzymes in Swiss albino mice. Phytother. Res., 13, 111-114.

5) Qureshi, M. A., Garlich, J. D. and Kidd, M. T. (1996) Dietary Spirulina platensis enhances humoral and cell mediated immune functions in chickens (submitted). Immunopharmacol. Immunotoxicol., 18, 465-476.
6) Qureshi, M. A., Kidd, M. T. and Ali, R. A. (1995) Spirulina platensis extract enhances chicken macrophage functions after in vitro exposure. J. Nutr. Immunol., 3, 35-45.

7) Verma, S. (2000) Chemical modification of radiation response in Swiss albino mice, $\mathrm{Ph}$. D. Thesis, University of Rajasthan, Jaipur, India.

8) Shastri, D. (1999) Modulation of heavy metal induced toxicity in the testes of Swiss albino mice by certain plant extracts, $\mathrm{Ph}$. D. thesis, University of Rajasthan, Jaipur, India.

9) Saxena, P. S. and Kumar, M. (2004) Modulatory potential of Spirulina fusiformis on testicular phosphatases in Swiss albino mice against mercury intoxication. Indian J. Exp. Biol., 42, 998-1002.

10) Kind, P. R. N. and King, E. J. (1954) Estimation of plasma phosphatase by determination of hydrolysed phenol with amino-antipyrine. J. Clin. Pathol., 7, 322.

11) Reitman, S. and Frankel, S. A. (1959) Colorimetric method for determination of serum glutamate oxaloacetate and glutamic pyruvic transaminases. Am. J. Clin. Pathol., 28, 56.

12) Okhawa, H., Ohishi, N. and Yagi, K. (1979) Assay for lipid peroxidation in animal tissue by thiobarbituric acid reaction. Anal. Biochem., 95, 351.

13) Moron, M. J., Depierre, J. W. and Mannlrvik, B. (1979) Levels of GSH, GR and GST activities in rat lungs and liver. Biochem. Biophys. Acta, 582, 67.

14) Vandenberghe, J. (1995) Hepatotoxicology: Mechanisms of liver toxicity and methodological aspects. In Toxicology: Principle and applications (Niesink, J. M., Vries, J. D. and Hollinger, M. A., Eds.), CRC Press, Boca Raton, p. 718.

15) Rana, S. V. S., Singh, R. and Verma, S. (1996) Protective effects of few antioxidants on liver function in rats treated with cadmium and mercury. Indian $J$. Exp, Biol., 34, 177.

16) Sharma, M. K., Kumar, M. and Kumar, A. (2002) Ocimum sanctum aqueous leaf extract provides protection against mercury induced toxicity in Swiss albino mice. Indian J. Exp. Biol., 40, 1079-1082.

17) Sharma, M. K., Kumar, M. and Kumar, A. (2000) Study of mercury induced toxicity in liver and its modulation by Spirulina fusiformis and Ocimum sanctum, Published in Proceedings of $3^{\text {rd }}$ World Congress on Cellular and Molecular Biology held in Jena, Germany. Cell. Mol. Biol., 46, 227.

18) Sharma, M. K., Kumar, M. and Kumar, A. (2001) Modulatory influence of Ocimum sanctum and Spirulina fusiformis against mercury induced toxicity in liver. Bull. Environ. Sci., 19, 85-91.

19) Hardonk, M. J. and Koudstaal, J. (1976) Enzyme histochemisty as a link between biochemistry and 
morphology. Gustav Fischer, Stuttgart, 40.

20) El-Demerdash, F. M. (2001) Effects of selenium and mercury on the enzymatic activities and lipid peroxidation in brain, liver and blood of rats. $J$. Environ. Sci. Health B, 36, 489.

21) Ketterer, B., Coles, B. and Meyer, D. J. (1983) The role of glutathione in detoxication. Environ. Health Perspect., 49, 59.

22) Meister, A. and Andersen, M. E. (1983) Glutathione. Annu. Rev. Biochem., 52, 711.

23) Zalups, R. K. and Lash, L. H. (1996) Interactions between Glutathione and mercury in the kidney, liver and blood. In Toxicology of Metals (Chang, L. W., ed.), CRC Press, Boca Raton, p. 145.

24) Prescott, G. W. (1978) How to know the fresh water algae? $3^{\text {rd }}$ ed., Wn. C. Brown Company Publishers, Iowa, U.S.A., p. 182.

25) Seshadri, C. V., Umesh, B. V. and Manoharan, R. (1991) $\beta$-Carotene studies in Spirulina. Biores Tech., 38, 111-113.

26) Mathew, B., Sankaranarayanan, R., Nair, P. P., Varghese, P., Somanthan, T., Amma, B. P., Amm, N. S. and Nair, M. K. (1995) Evaluation to chemoprevention of oral cancer with Spirulina fusiformis. Nutr. Cancer, 24, 194-202.

27) Ben-Amotz (1997) Presentation of polysaccharides from micro algae workshop, Duke University.

28) Henrikson, R. (1989) Earth food Spirulina, Cited from Recolina Ltd., Ronore enterprises Inc., Launa Beach, California, pp. 27-65.

29) Foote, C. F., Chang, Y. C. and Denny, R. W. (1970) Chemistry of singlet oxygen. $\mathrm{X}$. Carotenoids quenching parallels biological protection. J. Am. Chem. Soc., 92, 5216-5219.
30) Krinsky, N. I. and Deneke, S. M. (1982) Interaction of oxygen and oxyradicals with carotenoids. J. Nat. Cancer Inst., 69, 205-210.

31) Luxia, A. S., Monica, S., Ornella, C., Plizzala, B., Laura, R., Livia, B., Anio, M. and Ennio, P. (1996) Effect of $\beta$-carotene on cell cycle progression of human fibroblasts. Mutagenesis, 17, 2395-2401.

32) Duval, C. and Poelman, M. C. (1994) Scavenger effect of vitamin $\mathrm{E}$ and derivatives on free radicals generated by photo irradiated phenomelanin. $J$. Pharm. Sci., 84, 107-110.

33) Kulkarni, A. P. and Byczkowski, J. Z. (1994) Hepatoxicity. In Introduction to biochemical toxicology, $2^{\text {nd }}$ ed. (Hodgson, E. and Levi, P. E., eds.), Appleton \& Lange, London, pp. 103-105.

34) Patil, G. R. and Rao, M. V. (1999) Role of ascorbic acid on mercuric chloride toxicity in vital organs of mice. Indian J. Environ. Toxicol., 9, 53-55.

35) Rao, M. V. and Sharma, P. S. N. (2001) Protective effect of Vitamin E against mercuric chloride reproductive toxicity in male mice. Reprod. Toxicol., 15, 705-712.

36) Lindh, U., Danersaund, A. and Lindvall, A. (1996) Selenium protection against toxicity from cadmium and mercury studied at cellular level. Cell. Mol. Biol., 42, 39-48.

37) Girardi, G. and Elias, M. M. (1995) Mercuric chloride effects on rat renal redox enzymes activities: SOD protection. Free Radic. Biol. Med., 18, 61-66.

38) Hayashi, O., Koloh, T. and Ikiwaki, Y. (1994) Enhancement of antibody production in mice by dietary Spirulina platensis. J. Nutri. Sci. Vitaminol. (Tokyo), 40, 431-441. 